\title{
Alternative Level of Care in Canada: A Summary
}

\author{
Jennifer D. Walker, Kathleen Morris and Jennifer Frood
}

anadian health system managers are increasingly concerned about the number of hospital in-patients who do not need acute care services (Ontario Association for Community Care Access Centres et al. 2006; Yassi et al. 2008). These patients are widely known as "ALC patients" because they are awaiting an alternative level of care in a more appropriate setting. ALC days in hospitals is a systems issue, reflecting challenges in different parts of the healthcare system, including hospitals, community care and long-term care (MacLeod et al. 2008; Ontario Association for Community Care Access Centres et al. 2006; Penney and Henry 2008). Planning and coordination across health sectors will be enhanced through a better understanding of the characteristics of ALC patients and what happens after they are discharged from hospital.

This article summarizes more detailed findings presented in the recent report by the Canadian Institute for Health Information (CIHI 2009), Waiting in Hospital: Alternate Level of Care in Canada.

\section{Data Sources and Methods}

Hospitalization data were obtained from CIHI's Discharge Abstract Database (DAD) 2007-2008. This database captures administrative, clinical and demographic information for in-patients across Canada. This study includes patients discharged between April 1, 2007, and March 31, 2008.

Despite standardized ALC data collection in the DAD since 1989 , little reporting of these data has taken place. This is
Figure 1. Scope of ALC by province, 2007-2008

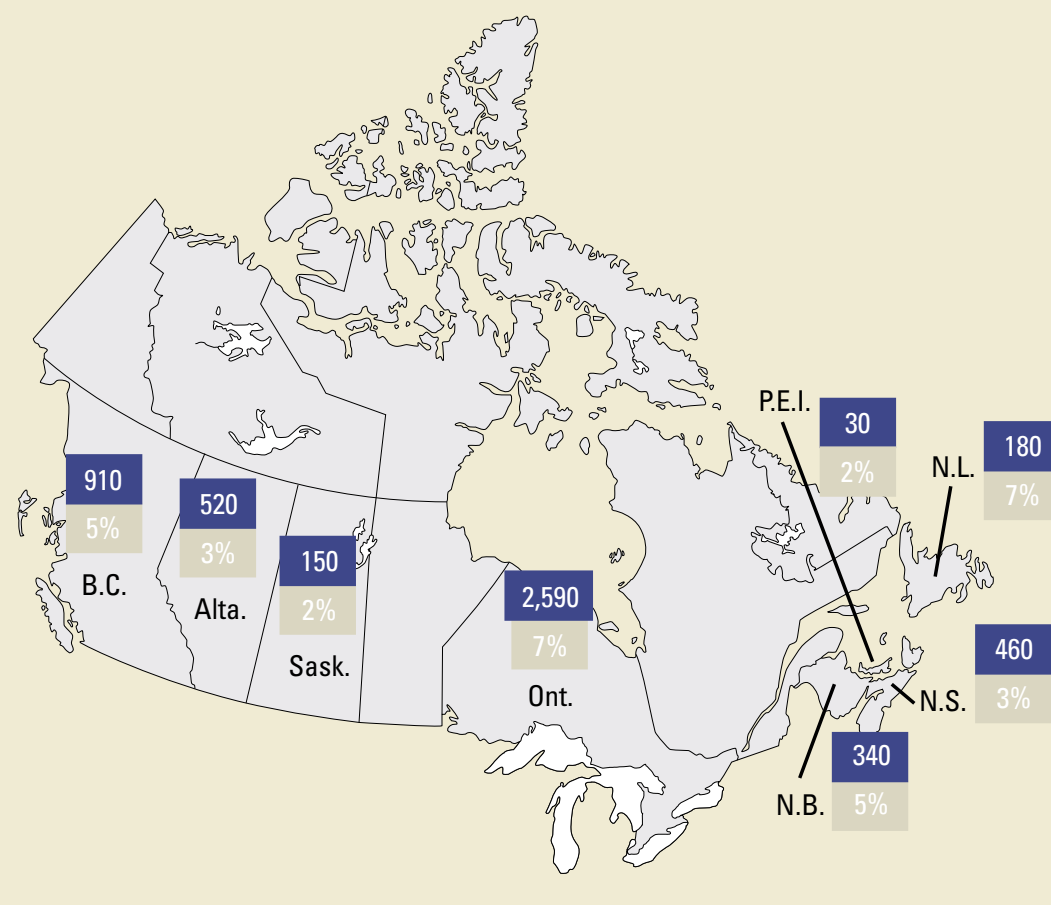

No. of hospital bed-equivalents used for alternative level of care (ALC), assuming $90 \%$ occupancy, rounded to the nearest 10 beds.

$\%$ of hospitalizations that were ALC related.

Notes: ALC may be defined and recorded differently in different provinces. Excludes abstracts from Manitoba and Quebec as well as obstetrical and pediatric patients. Data for territories not reported due to small numbers that result in rate instability. Source: Discharge Abstract Database, 2007-2008, Canadian Institute for Health Information. primarily due to concerns about variations in the reporting of ALC data that prevent comparability across facilities and jurisdictions. To improve comparability, several known sources of ALC reporting variation were addressed by excluding data from Quebec and Manitoba as well as all pediatric and obstetric cases from the analysis. Data from the territories are included in the 
overall analyses but are not reported by territory due to small numbers that result in rate instability.

\section{Key Findings}

In $2007-2008,5 \%$ of hospitalizations $(N=74,504)$ and $14 \%$ of hospital days ( $N=1.7$ million) involved ALC patients. The

Table 1. Characteristics of ALC and non-ALC patients, 2007-2008

\begin{tabular}{|l|c|c|}
\hline & ALC Patients & Non-ALC Patients \\
\hline Female (\%) & 58 & 51 \\
\hline Age (median years) & 80 & 63 \\
\hline At least one comorbidity (\%) & 36 & 15 \\
\hline Admitted through the ED (\%) & 83 & 63 \\
\hline Length of hospitalization (median days) & \multicolumn{2}{|c|}{} \\
\hline Total & 26 & 4 \\
\hline Acute portion & 11 & 4 \\
\hline ALC portion & 10 & - \\
\hline
\end{tabular}

$\mathrm{ALC}=$ alternative level of care; $\mathrm{ED}=$ emergency department.

Source: Discharge Abstract Database, 2007-2008, Canadian Institute for Health Information.

Figure 2. Distribution of ALC length of stay, 2007-2008*

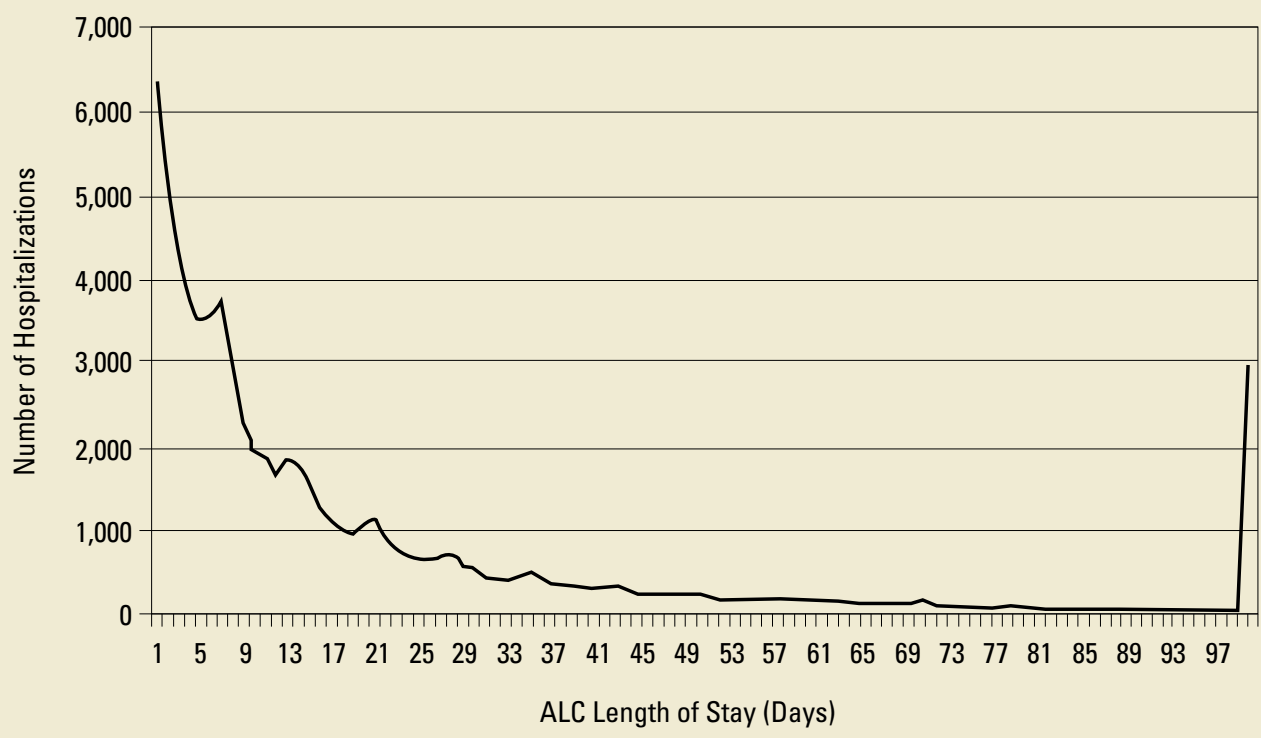

*69,445 patients were admitted for 74,504 hospitalization episodes that had alternative level of care (ALC) days.

Source: Discharge Abstract Database, 2007-2008, Canadian Institute for Health Information. provincial range for ALC hospitalizations was $2-7 \%$ of all hospitalizations (Figure 1).

\section{ALC Patient Profile}

ALC patients were older than non-ALC patients and were more likely to begin their hospital experience in an emergency department (Table 1). ALC patients were also more than twice as likely to have a comorbid condition as measured by the Charlson Comorbidity Index (Sundararajan et al. 2004). Dementia, as a main or comorbid diagnosis, accounted for almost one quarter of ALC hospitalizations and more than one third of ALC days. Patients with dementia as a main diagnosis had a median ALC length of stay of 23 days compared with 10 days for ALC patients overall.

\section{ALC Length of Stay}

Wide variation was observed in ALC days, ranging from one to more than 100 days (Figure 2). Longstay patients (>100 ALC days) did not differ from other patients on demographic variables (gender and age) but were more likely to be in the hospital for reasons related to dementia.

\section{ALC Patients after Discharge}

Overall, the predominant discharge destination $(43 \%)$ was to a long-term care facility (Figure 3). More than one quarter of ALC patients were discharged home. Seventeen (17\%) percent of these patients were readmitted to hospital within 30 days. This compares to $12 \%$ for non-ALC patients discharged home. Of the $12 \%$ who died during their ALC hospitalization, $42 \%$ were receiving palliative care and $45 \%$ were awaiting admission to another facility.

\section{Discussion}

This issue of ALC is a sizeable challenge for hospitals and health 
Figure 3. Discharge destinations for ALC patients, 2007-2008 (\%)

12

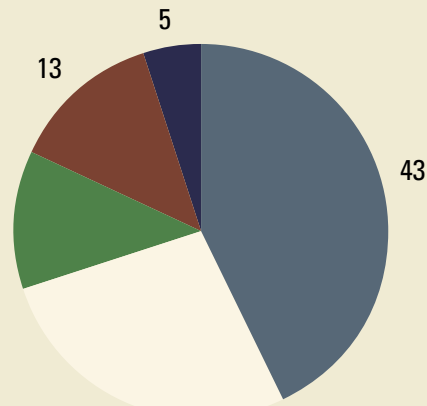

27
Long-Term Care Home (With/Without Support)

Died

Rehabilitation Facility

Other

Source: Discharge Abstract Database, 2007-2008, Canadian Institute for Health Information.

system managers in Canada, with over 1.7 million hospital days used for ALC outside of Manitoba and Quebec in 2007-2008. ALC patients were older and had diagnostic, comorbidity and length-of-stay profiles that indicate complex follow-up care requirements. Most ALC patients were waiting for placement and were discharged to a long-term care facility. However, other ALC care paths included patients waiting for placement and discharged home or dying before discharge could occur.

The reasons for provincial and facility variations in the number of ALC patients and days are not well understood. Differences in funding and system capacity may account for some of the variation. However, ALC variation may also arise from differences in documentation and data collection. CIHI is involved in follow-up work to better understand variation in ALC reporting in order to improve the comparability of ALC data across Canada.

Despite some limitations, ALC data can shed light on questions about the continuity of care for patients as they transition out of acute care. For example, results from a recent CIHI study, Patient Pathway: Transfers from Continuing Care to Acute Care. found that new long-term care admissions accounted for most of the ALC waits for long-term care beds. Only $4 \%$ of residents who were hospitalized and discharged back to the same long-term care setting experienced ALC days in hospital. Efforts to improve our understanding of ALC can help to answer broader policy questions about the capacity of different sectors to effectively care for patients as they move through the system. HQ

\section{References}

Canadian Institute for Health Information. 2009. Waiting in Hospital: Alternate Level of Care in Canada. Ottawa, ON: Author. Retrieved February 12, 2009. <http://secure.cihi.ca/cihiweb/dispPage.jsp?cw_ page=AR_2610_E>.
MacLeod, H., B. Bell, K. Deane and C. Baker. 2008. "Creating Sustained Improvements in Patient Access and Flow: Experiences from Three Ontario Healthcare Institutions." Healthcare Quarterly 11(3): 38-49.

Ontario Association for Community Care Access Centres, Ontario Association of Non-Profit Homes and Services for Seniors, Ontario Hospital Association, Ontario Long Term Care Association. 2006. Alternate Level of Care - Challenges and Opportunities. A Collaborative Position Paper. Toronto, ON: Ontario Hospital Association. Retrieved October 31, 2008. <http://www.oha.com/ Client/OHA/OHA_LP4W_LND_WebStation. $\mathrm{nsf} / \mathrm{resources} /$ Alternate + Level + of + Care++Challenges+and+Opportunities/\$file/Alternate_ LevelofCare_May2006.pdf>.

Penney, C. and E. Henry. 2008. "Improving Performance Management for Delivering Appropriate Care for Patients No Longer Needing Acute Hospital Care." Journal of Health Services Research and Policy 13(Suppl. 1): 30-34.

Sundararajan, V., T. Henderson, C. Perry, A. Muggivan, H. Quan and W.A. Ghali. 2004. "New ICD-10 Version of the Charlson Comorbidity Index Predicted In-Hospital Mortality." Journal of Clinical Epidemiology 57: 1288-94.

Yassi, A., A. Ostry, P.A. Ratner, R. Tate, I.H. Park, A. Kazanjian, H. MacLeod, C. Kidd, D. Keen, L. Felkar, S. Saunders, M. Arbogast, M. Cohen and R. Notley. 2008. Caring for the Caregivers of "Alternate Level Care" (ALC) Patients: The Impact of Healthcare Organizational Factors in Nurse Health, Well Being, Recruitment and Retention in the South Fraser Health Region of British Columbia. Vancouver, BC: Occupational Health and Safety Agency for Healthcare in B.C. Retrieved October 31, 2008. <http://www.ohsah.bc.ca/media/1-ALC-Final-Report.pdf>.

Canadian Institute for Health Information. 2009. Patient Pathways: Transfers From Continuing Care to Acute Care. Ottawa, ON: Author. Retrieved February 12, 2009. http://secure.cihi.ca/cihiweb/dispPage. jsp?cw_page=PG_1770_E\&cw_topic=1770\&cw_rel=AR_2630_E.

\section{About the Authors}

Jennifer $\mathrm{D}$. Walker, $\mathrm{PhD}$, is a special project lead with the Canadian Institute for Health Information (CIHI). In her role, she leads and contributes to analytical and special projects within CIHI's Western Canada and Research and Analysis Divisions. (Toronto)

Kathleen Morris, MBA, is a consultant who has assisted $\mathrm{ClHI}$ with several projects, providing leadership for new wait times, quality and patient safety initiatives. (Toronto)

Jennifer Frood, MSc, is a senior analyst with the $\mathrm{CIHI}$ Research and Analysis Division. (Toronto) 